Research Article

\title{
Deformation and Failure Mechanism of Surrounding Rock in Mining-Influenced Roadway and the Control Technology
}

\author{
Jicheng Feng $(\mathbb{D}$, Shuaifeng Yin $(\mathbb{D}$, Zhiheng Cheng, Jianjun Shi, Haoyu Shi, Haitao Xu, \\ and Shuying Guo
}

Safety Engineering College, North China Institute of Science and Technology, Langfang 065201, China

Correspondence should be addressed to Shuaifeng Yin; 296741972@qq.com

Received 6 February 2021; Revised 18 March 2021; Accepted 7 April 2021; Published 19 April 2021

Academic Editor: Haiyan Wang

Copyright $\odot 2021$ Jicheng Feng et al. This is an open access article distributed under the Creative Commons Attribution License, which permits unrestricted use, distribution, and reproduction in any medium, provided the original work is properly cited.

\begin{abstract}
Aiming at the problem of surrounding rock deformation and failure of mining roadway and its control, a mechanical model of the circular roadway under the mining environment is established, and the implicit equation of the plastic zone boundary is derived. By analyzing the morphologic evolution law of the surrounding rock plastic zone in the mining roadway, the key factors affecting the morphologic change of the plastic zone are obtained, that is, the magnitude and direction of principal stress. The influence law of the magnitude and direction of principal stress on the plastic zone of the mining roadway is analyzed by using numerical simulation software, and the deformation and failure mechanism of surrounding rock of the mining roadway is revealed. The results showed that the size and morphology of the plastic zone were closely related to the confining pressure ratio $(\eta)$. Taking the boundary of $\eta$ valuing 1 , the larger or smaller $\eta$ value was, the more serious the deformation and failure of surrounding rock would be; the morphology of the plastic zone changed with the deflection of the principal stress, with the location of the maximum plastic zone influenced by the principal stress direction. For the surrounding rock control in the mining-influenced roadway, it is advised to take the following methods: firstly, it is necessary to consider how to reduce or remove the influence of mining on surrounding rock, improve the stress environment of surrounding rock, and reduce the failure depth of the plastic zone, so as to better maintain the roadway. Secondly, in view of the deformation and failure characteristics of the mining roadway, the fractional support method of "yielding first and then resisting" should be adopted, which applies the cable supplement support after mining instead of the one-off high-strength support during roadway excavation, so as to control the malignant expansion of the surrounding rock plastic zone and prevent roof falling accidents.
\end{abstract}

\section{Introduction}

The mining-influenced roadway is an important part of underground coal mining, which directly serves the working face [1-4]. Affected by one or more mining operations, the surrounding rock of the roadway is deformed, the supporting body fails, and even the roof collapses, which makes the roadway maintenance extremely difficult [5-7]. Therefore, it is of great significance to study the deformation and failure mechanism of the mining-influenced roadway and its control technology [8-10].

A lot of research studies have been carried out by many experts and scholars in the deformation of mining-influenced roadway surrounding rock and the damage control.
Zhao et al. $[11,12]$ analyzed the influence of the nonuniform stress field on the morphology and size of the tunnel plastic zone under the influence of mining and put forward the theory of butterfly-shaped plastic zone. The stability control technology of the surrounding rock with a long bolt is studied and applied in the face of the butterfly failure roadway. Considering the stress environment of surrounding rock of the deep mining roadway, Ma et al. [13, 14] proposed the mechanical mechanism of the formation of the plastic zone in surrounding rock under nonisobaric conditions and its morphological and discussed the influencing factors of roof stability. Yuan et al. $[15,16]$ clarified the mechanical conditions for the formation of class I and class II butterfly-shaped plastic zones by further studying the 
morphological evolution law of plastic zones in the deep dynamic pressure roadway and defined the malignant expansion and criticality of plastic zones. He et al. $[17,18]$ analyzed the root cause and process of the failure and instability of the coal roadway which was affected by the intense mining in the large adjacent fully mechanized caving face and proposed anchor cable truss and grouting supporting technologies. Chen et al. $[7,19]$ studied the mechanical mechanism of complex deformation of the deep dynamic pressure roadway, and they believed that the size and direction of the surrounding rock stress field changed due to mining disturbance, which was the main factor causing the asymmetric deformation of the roadway. Therefore, an asymmetric multimode coupling control strategy is proposed. Hui et al. [20] explored the deformation evolution law of surrounding rock in a gob-side roadway subjected to dynamic pressure through physical simulation and pointed out that intense mining obstructs the control of surrounding rock. The above research results play an important role in the control of surrounding rock in the mining roadway.

Because of the complexity and difference of geological environment and mining conditions of the coal seam, the deformation and failure mechanism of surrounding rock of the mining roadway are different. The problem of surrounding rock stability control has not been completely solved. Therefore, further research is still needed. In this paper, based on elastic-plastic theory, a mechanical model of the circular roadway under the mining environment was established, and the plastic zone boundary implicit equation was inferred. Based on the numerical simulation with the implicit equation applied, this paper analyzed the morphological evolution law of the roadway plastic zone, revealed the deformation failure mechanism of the mininginfluenced roadway, and introduced roadway surrounding rock control methods.

\section{Deformation and Failure Characteristics of Surrounding Rock in the Mining- Influenced Roadway}

The mining roadway should not only bear the influence of driving disturbance but also bear the intense influence of the mining of the working face and its adjacent working face from opening to scrapping [21]. The stress field of surrounding rock in the mining-influenced roadway is complex, which is the combination of the initial stress field, excavation stress field, and mining stress field. Therefore, the deformation and failure of the mining roadway are closely related to the complex stress field around it. The interaction between the stress environment and the mechanical properties of surrounding rock results in the severe deformation and failure of most mining roadways [22].

The statistical data show the relationship between the buried depth of the roadway and the stability of surrounding rock [23]. The surrounding rock deformation and failure are not obvious after the excavation of the roadway with a buried depth of $200 \mathrm{~m} \sim 400 \mathrm{~m}$, and the surrounding rock deformation and failure are not obvious until it is affected by the intense mining. Surrounding rock deformation and failure will occur in the tunnel with a buried depth greater than $400 \mathrm{~m}$ during tunneling, and severe deformation and failure will occur in the surrounding rock under the influence of mining [24]. A large number of investigation data have summarized the deformation and failure characteristics of the mining roadway, as shown in Figure 1.

(1) The severe roof sag can reach $200 \sim 1000 \mathrm{~mm}$, as shown in Figure 1(a). In the stage of strong mining influence, even the local roof caving appears.

(2) The coal body at the side was seriously damaged, with the phenomenon of "net pocket" and "net breaking" appearing, and the bulging volume at the side could reach $200 \sim 1000 \mathrm{~mm}$, as shown in Figure 1(b).

(3) The floor heave of the roadway leads to concrete cracking damage, which makes it difficult for pedestrians and traffic. The floor deformation can reach 200 1500 mm, as shown in Figure 1(c).

(4) In the complex mining stress and heterogeneous rock mass environment, the surrounding rock exhibits nonuniform deformation, such as roof step subsidence and different deformation and failure locations of the surrounding rock surface, as shown in Figures 1(d) and 1(e).

(5) The bolt fails because its length is less than the range of damaged surrounding rock, and the cable fails because its elongation is too small to resist the large deformation of surrounding rock, as shown in Figure 1(f). Roof collapse is easy to occur when the support body is damaged seriously without timely supplement of anchor bolts and cables.

\section{Theoretical Analysis of the Plastic Zone in Mining-Influenced Roadway Surrounding Rock}

3.1. Fundamental Theory. Referring to the previous research results $[25,26]$, this paper continues to discuss the change rule of the plastic zone of the circular roadway under the mining environment. The basic assumptions of the mechanical model are as follows (Figures 2 and 3).

(1) Level the roadway with infinite length, circular-cut face with a radius of $R_{0}$, and orebody depth $(H) \geq 20$ times radius.

(2) Surrounding rock mass is an isotropic homogeneous medium with plastic and incompressible properties.

(3) Extremely complex inhomogeneous high-stress field is formed by the superposition of initial stress and intense mining stress. Generally, there is an angle $\alpha$ between the stress direction and the vertical direction, as shown in Figure 2(a). To simplify the calculation, the direction of the model is changed into 


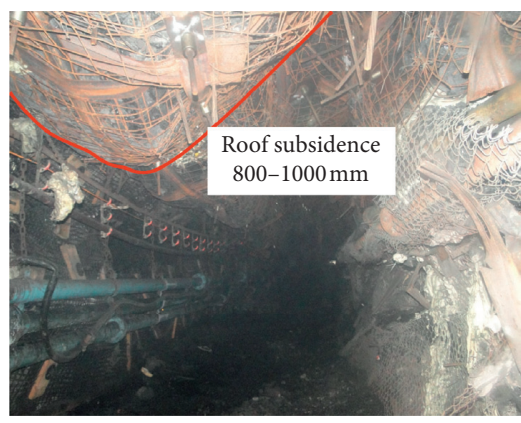

(a)

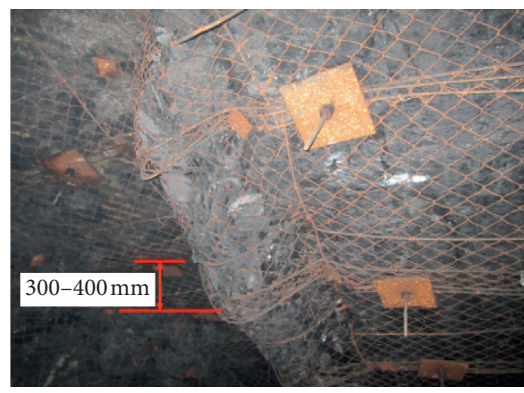

(d)

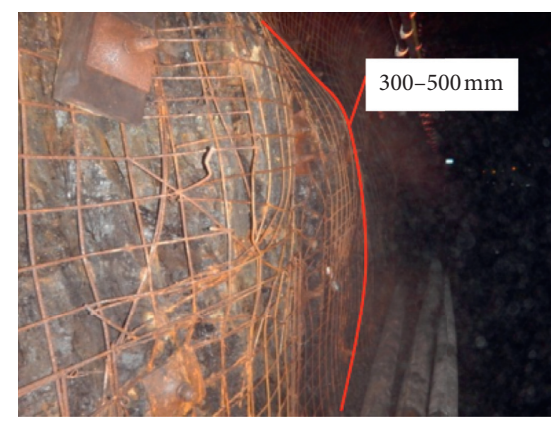

(b)

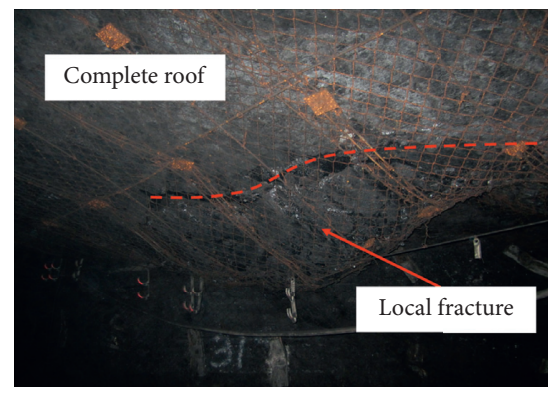

(e)

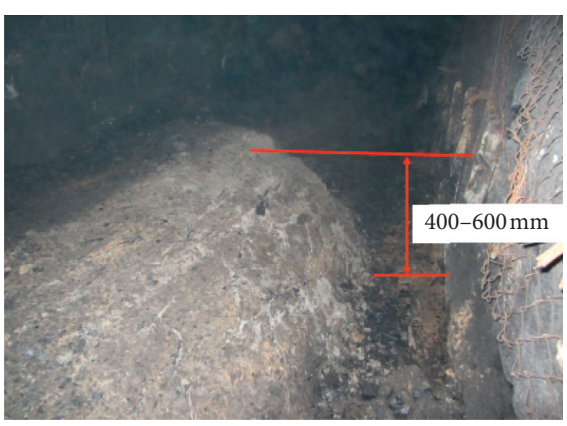

(c)

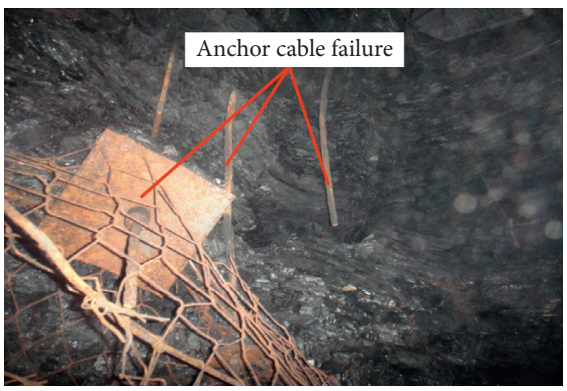

(f)

FIgURE 1: Deformation and failure characteristics of surrounding rock in the mining-influenced roadway.

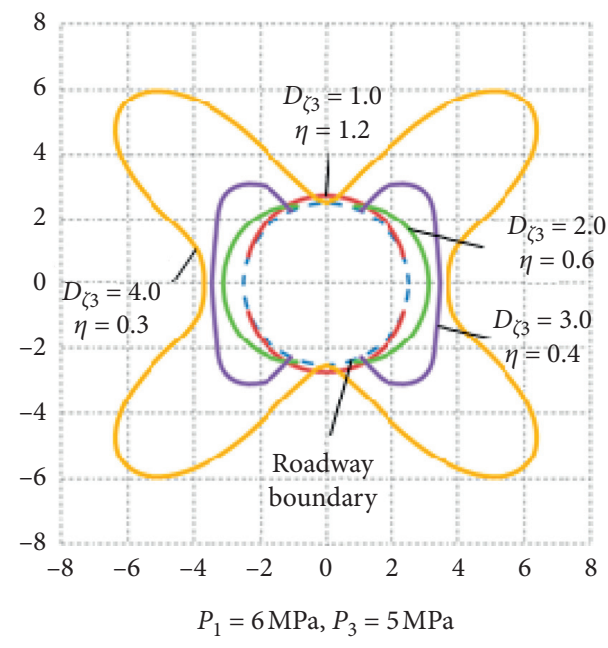

(a)

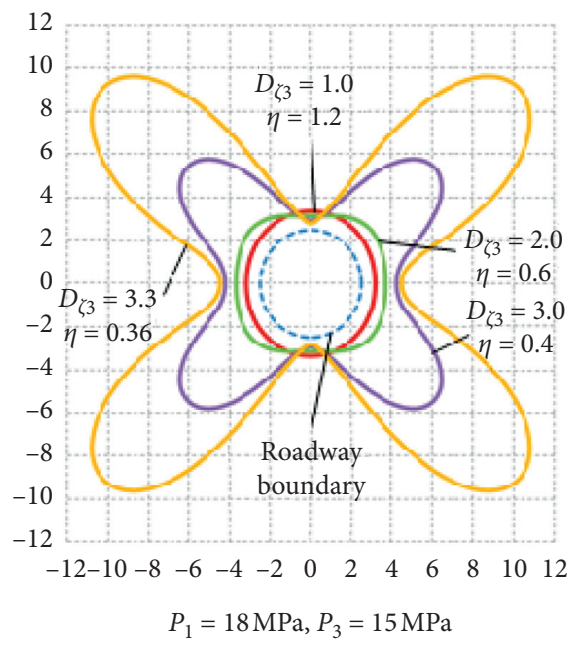

(b)

FIGURE 2: Morphology distribution of the roadway plastic zone influenced by the minimum principal stress.

vertical by contrarotating the angle $\alpha$, as shown in Figure 2(b). There is an assumption that $P_{1}$ is the maximum principal stress and $P_{3}$ is the minimum principal stress.

(4) Two parameters related to the coefficient of mining influence are introduced, which are the mining influence coefficient of maximum principal stress $D_{\zeta 1}$ and the mining influence coefficient of minimum principal stress $D_{\zeta 3}$. The stress model of surrounding rock under a certain loading condition is shown in Figure 3. In this model, surrounding rock can be divided into the plastic zone (radius $R_{p}$ ) and elastic zone from the center to edge.

According to the stress environment of surrounding rock of the mining roadway and the theory of elasticity, we can get the stress state of a certain point of surrounding rock of the circular roadway under the bidirectional nonisobaric condition: 


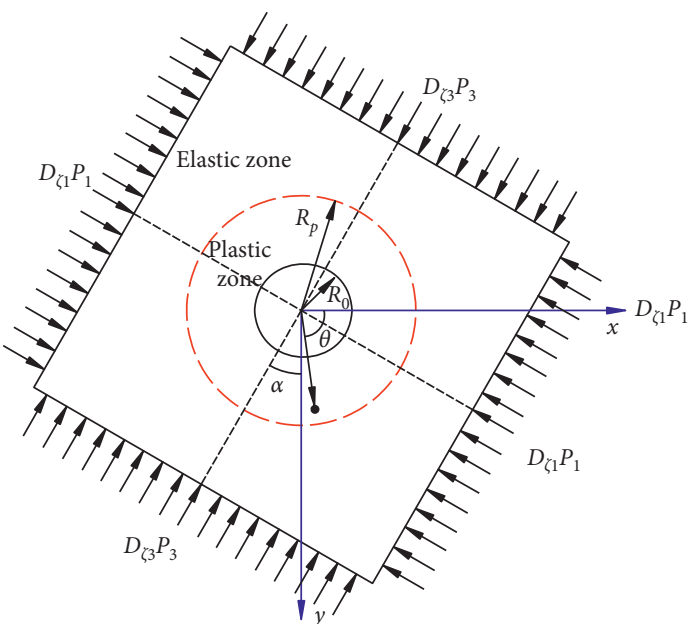

(a)

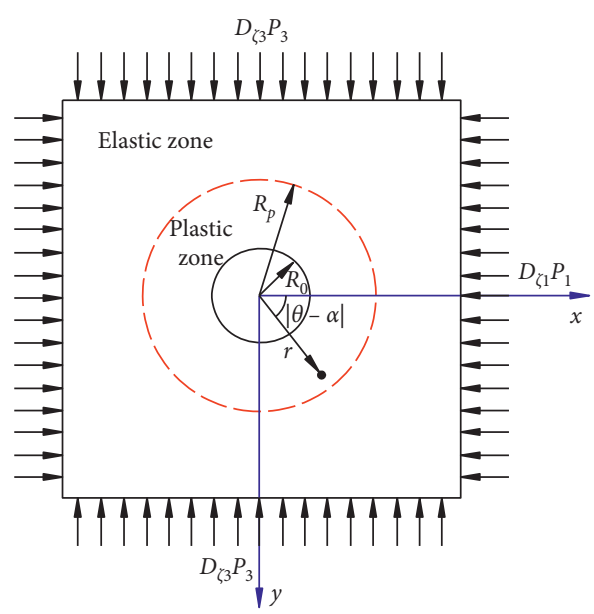

(b)

FIgURE 3: Mechanics model of the mining-influenced roadway.

$$
\left\{\begin{array}{l}
\sigma_{r}=\frac{D_{\zeta 1} P_{1}+D_{\zeta 3} P_{3}}{2}\left(1-\frac{R_{0}^{2}}{r^{2}}\right)+\frac{D_{\zeta 1} P_{1}-D_{\zeta 3} P_{3}}{2} \cos 2|\theta-\alpha|\left(1-\frac{R_{0}^{2}}{r^{2}}\right)\left(1-3 \frac{R_{0}^{2}}{r^{2}}\right) \\
\sigma_{\theta}=\frac{D_{\zeta 1} P_{1}+D_{\zeta 3} P_{3}}{2}\left(1+\frac{R_{0}^{2}}{r^{2}}\right)-\frac{D_{\zeta 1} P_{1}-D_{\zeta 3} P_{3}}{2} \cos 2|\theta-\alpha|\left(1+3 \frac{R_{0}^{2}}{r^{2}}\right) \\
\tau_{r \theta}=-\frac{D_{\zeta 1} P_{1}-D_{\zeta 3} P_{3}}{2} \sin 2|\theta-\alpha|\left(1-\frac{R_{0}^{2}}{r^{2}}\right)\left(1+3 \frac{R_{0}^{2}}{r^{2}}\right)
\end{array},\right.
$$

where $\sigma_{r}$ is radial stress, $\sigma_{\theta}$ is circumferential stress, $\tau_{r \theta}$ is shear stress $(\mathrm{MPa})$, and $r$ and $\theta$ are the polar coordinates of any point.

The equation of the Mohr-Coulomb criterion is expressed in the form of stress in polar coordinates, and the equation is

$$
\begin{aligned}
& \left(\frac{\sigma_{\mathrm{r}}-\sigma_{\theta}}{2}\right)^{2}+\left(\tau_{r \theta}\right)^{2}-\left(\frac{\sigma_{\mathrm{r}}+\sigma_{\theta}}{2}\right)^{2} \sin ^{2} \varphi \\
& \quad-\left(\sigma_{\mathrm{r}}+\sigma_{\theta}\right) \sin \varphi \cos \varphi C-C^{2} \cos ^{2} \varphi=0 .
\end{aligned}
$$

In equation (2), $x=\left(D_{\zeta 1} P_{1}+D_{\zeta 3} P_{3}\right) / 2, y=\left(D_{\zeta 1} P_{1}-D_{\zeta 3}\right.$ $\left.P_{3}\right) / 2, z=R_{0}{ }^{2} / r^{2}$, and $t=\cos 2|\theta-\alpha|$; substitute equation (1) into equation (2), then the binary implicit function (with two variables $r$ and $\theta$ ) is

$$
\begin{aligned}
f(r, \theta)= & {\left[\frac{y t}{2}\left(1-z+3 z^{2}\right)-2 x z\right]^{2}+y^{2}\left(1-t^{2}\right) } \\
& \cdot\left(1+2 z-3 z^{2}\right)-\left[2 x+y t\left(3 z^{2}-7 z\right)\right] \\
& \cdot\left\{\left[2 x+y t\left(3 z^{2}-7 z\right)\right] \sin \varphi-C \cos \varphi\right\} \\
& -C^{2} \cos ^{2} \varphi
\end{aligned}
$$

In this equation, $C$ is the internal cohesion of surrounding rock $(\mathrm{MPa})$ and $\varphi\left(^{\circ}\right)$ is the internal friction angle.
The above equation shows that $r$ is related to the parameters $P_{1}, D_{\zeta 1}, P_{3}, D_{\zeta 3}, \alpha, R_{0}, C$, and $R_{0}$, in which the first five parameters represent the stress of surrounding rock, $R_{0}$ is the radius of the roadway, and $C$ and $\varphi$ represent the mechanical properties of surrounding rock. Therefore, the plastic zone is mainly determined by the surrounding rock stress, when the roadway excavation size and surrounding rock parameters are determined. This paper focuses on the study of the influence law of the mining stress environment on the plastic zone.

3.2. Analysis of the Surrounding Rock Plastic Zone in MiningInfluenced Roadway. According to the boundary equation of the surrounding rock plastic zone in the mining-influenced roadway, the morphology of the plastic zone and its evolution are analyzed, and the internal relationship between the development, morphology distribution, and principal stress of the surrounding rock plastic zone is discussed. Calculation conditions: a circular roadway with a radius of $2.5 \mathrm{~m}$ is selected, which is in the homogeneous extrathick coal seam, where coal cohesion is measured as $3 \mathrm{MPa}$ and internal friction angle is $25^{\circ}$; two initial stress conditions of $P_{1}=6 \mathrm{MPa}$ and $P_{3}=5 \mathrm{MPa}$ and $P_{1}=18 \mathrm{MPa}$ and $P_{3}=15 \mathrm{MPa}$ (respectively, representing conditions of the static pressure roadway with orebody depths of $200 \mathrm{~m}$ and 
$600 \mathrm{~m}$, in which the side pressure coefficient is 1.2) are selected, and the confining pressure ratio $(\eta)$ is defined as $D_{\zeta 1} P_{1} / D_{\zeta 3} P_{3}$.

Figure 2(a) shows the morphology distribution of the plastic zone under the influence of minimum principal stress in the mining-influenced roadway with the orebody depth of $200 \mathrm{~m}$, where $D_{\zeta 1}$ is 1.0 and $D_{\zeta 3}$ is $1.0,2.0,3.0$, or 4.0 . When $D_{\zeta 3}$ is 1.0 , the shape of the plastic zone in the roadway is similar to a vertical ellipse, and its maximum size is $0.22 \mathrm{~m}$; when $D_{\zeta 3}$ is 2.0 , the shape of the plastic zone changes into a horizontal ellipse, and its maximum size is $0.59 \mathrm{~m}$; when $D_{\zeta 3}$ is 3.0 , the shape of the plastic zone is like a butterfly shape with the maximum size of $1.59 \mathrm{~m}$; when $D_{\zeta 3}$ is 4.0 , the butterfly-shaped plastic zone appears with the maximum size of $3.84 \mathrm{~m}$. Figure 2(b) shows the morphology distribution of the plastic zone under the influence of minimum principal stress in the mining roadway with the orebody depth of $600 \mathrm{~m}$, in which $D_{\zeta 1}$ is 1.0 and $D_{\zeta 3}$ is $1.0,2.0,3.0$, or 3.3. When $D_{\zeta 3}$ is 1.0 , the shape of the plastic zone is similar to a vertical ellipse, and its maximum size is $0.86 \mathrm{~m}$; when $D_{\zeta 3}$ is 2.0 , the shape of the plastic zone is similar to a rectangle, and its maximum size is $1.38 \mathrm{~m}$; when $D_{\zeta 3}$ is 3.0 , the butterflyshaped plastic zone appears with the maximum size of $5.64 \mathrm{~m}$; when $D_{\zeta 3}$ is 3.3 , the shape of the plastic zone does not change with its maximum size of $11.2 \mathrm{~m}$.

Figure 4(a) shows the morphology distribution of the plastic zone under the influence of maximum principal stress in the mining-influenced roadway with the orebody depth of $200 \mathrm{~m}$, where $D_{\zeta 3}$ is 1.0 and $D_{\zeta 1}$ is $1.0,2.0,3.0$, or 4.0. When $D_{\zeta 3}$ is 1.0, the shape of the plastic zone is like a vertical ellipse, and its maximum size is $0.22 \mathrm{~m}$; when $D_{\zeta 3}$ is 2.0 , the shape of the plastic zone is like a butterfly shape, and its maximum size is $0.88 \mathrm{~m}$; when $D_{\zeta 3}$ is 3.0 , the shape of the plastic zone changes into a butterfly with the maximum size of $5.86 \mathrm{~m}$; when $D_{\zeta 3}$ is 3.3 , the butterfly-shaped plastic zone appears with the maximum size of $10.97 \mathrm{~m}$. Figure 4(b) shows the morphology distribution of the plastic zone under the influence of maximum principal stress in the mining roadway with the orebody depth of $600 \mathrm{~m}$, in which $D_{\zeta 1}$ is 1.0 and $D_{\zeta 3}$ is $1.0,2.0,2.2$, and 2.4. When $D_{\zeta 3}$ is 1.0 , the shape of the plastic zone is like a vertical ellipse, and its maximum size is $0.86 \mathrm{~m}$; when $D_{\zeta 3}$ is 2.0 , the shape of the plastic zone changes into a butterfly, and its maximum size is $4.02 \mathrm{~m}$; when $D_{\zeta 3}$ is 2.2 , the butterfly-shaped plastic zone remains with the maximum size of $5.83 \mathrm{~m}$; when $D_{\zeta 3}$ is 2.4 , the maximum size of the butterfly-shaped plastic zone expands into $12.27 \mathrm{~m}$.

In conclusion, it can be seen from Figures 4 and 5 that mining activities have a significant influence on the morphology distribution of the surrounding rock plastic zone. The shape and size of the plastic zone change with the mining coefficient decided by the maximum and minimum principal stresses of surrounding rock. Under the influence of mining, the maximum and minimum principal stresses vary. The boundary confining pressure ratio $(\eta)$ value is 1 . The larger or smaller value of $\eta$ is, the more serious the deformation and failure of the surrounding rock plastic zone will be and the more severe the malignant expansion of the plastic zone will be.
Figure 5 shows the morphology distribution of the plastic zone in roadways influenced by the change of the principal stress direction. When the direction of principal stress is the vertical direction $\left(\alpha=0^{\circ}\right)$, the largest plastic zone is located in the roadway shoulder; when the principal stress deflects clockwise $45^{\circ}\left(\alpha=45^{\circ}\right)$, the largest plastic zone is located on roadway roof, floor, and two sidewalls, and the plastic zone also rotates $45^{\circ}$; when the principal stress deflects clockwise $90^{\circ}\left(\alpha=90^{\circ}\right)$, the largest plastic zone lies on the top shoulder of the roadway, and plastic zones also rotate $90^{\circ}$. It can be seen that, under the condition of homogeneous surrounding rock, when the direction of principal stress changes, the size of the plastic zone will not change, but the plastic zone direction will deflect. Under the influence of mining, the direction of principal stress will change. When $\alpha$ is $45^{\circ}$, the sizes of the surrounding rock plastic zone on roof, floor, and two sidewalls represent larger. As a result, roof collapse, rib spalling, and floor heave easily occur, obstructing the maintenance of the roadway.

\section{Deformation and Failure Mechanism of Surrounding Rock in the Mining- Influenced Roadway}

The field measurement shows that the intense mining influence not only changes the magnitude of the surrounding rock stress field but also changes the direction of the stress field to some extent. This can be reflected in some coal mine pressure phenomena, such as large deformation of the roadway and nonuniform failure of the surrounding rock. Therefore, a study on the distribution characteristics of the surrounding rock plastic zone in the roadway through researching of the complex stress field contributes to further revealing of the deformation and failure mechanism of the surrounding rock. In the following analysis, the FLAC ${ }^{3 \mathrm{D}}$ finite differential method is applied to conduct a numerical study on the morphology characteristics of the surrounding rock plastic zone in the mining-influenced roadway [27, 28].

4.1. Numerical Calculation Model and Parameters. The size of the model is $50 \mathrm{~m} \times 50 \mathrm{~m} \times 1 \mathrm{~m}$ (width $\times$ height $\times$ thickness), and the roadway size is $5 \mathrm{~m} \times 3.5 \mathrm{~m}$. The grid is divided into hexahedral units. The model boundaries are all subject to displacement constraints. The Mohr-Coulomb strength model is used for rock material simulation, and the material mechanical parameters are shown in Table 1.

To verify the morphological distribution of the plastic zone of roadway surrounding rock under the influence of mining, we designed a simulation scheme under different mining environments. The mining coefficient and deflection angle are mainly considered in the scheme. In the scheme, $P_{1}$ is $18 \mathrm{MPa}, P_{3}$ is $15 \mathrm{MPa}$, and the lateral pressure coefficient is 1.2. The first scheme fixed the mining coefficient and changed the deflection angle, as shown in Table 2. The second scheme fixed the deflection angle and changed the mining coefficient, as shown in Table 3. 


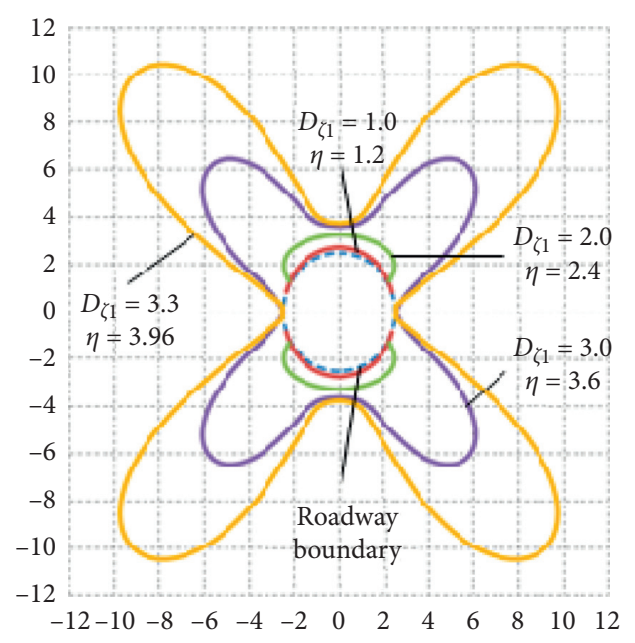

(a)

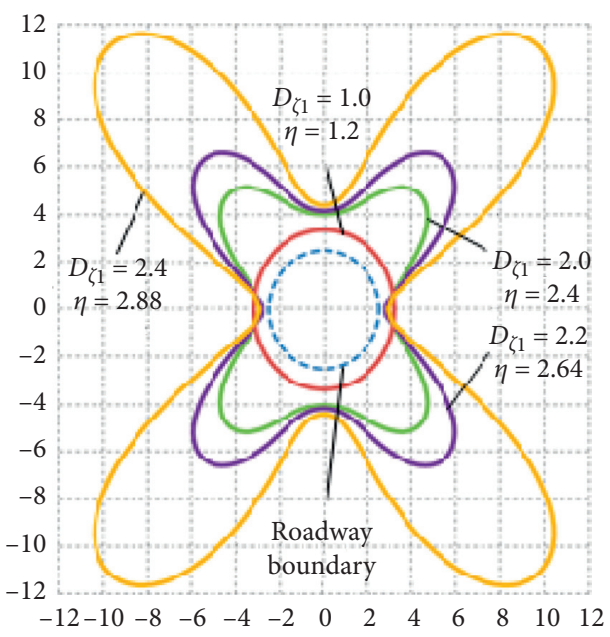

(b)

Figure 4: Morphology distribution of the roadway plastic zone influenced by the maximum principal stress.

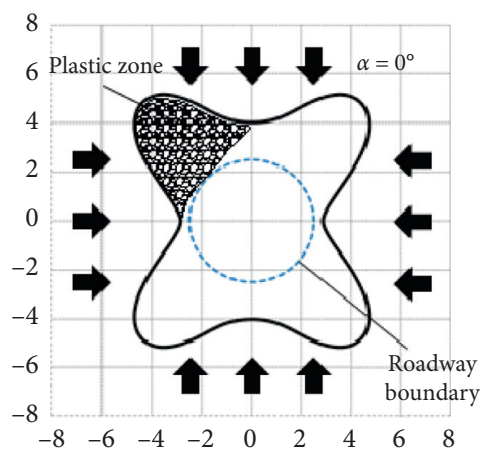

(a)

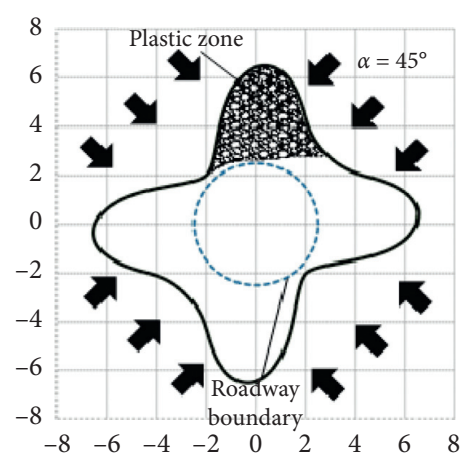

(b)

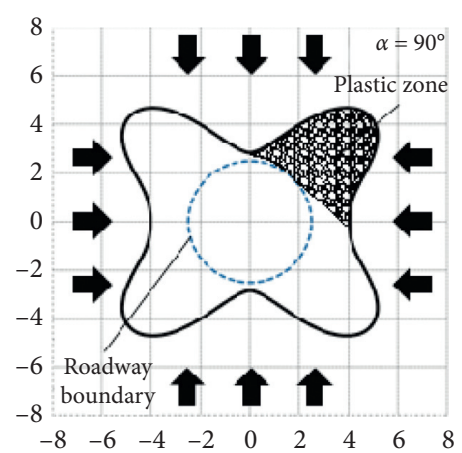

(c)

FIGURE 5: Morphology distribution of the roadway plastic zone influenced by the change of the principal stress direction.

TABle 1: Physical and mechanical parameters of each rock stratum.

\begin{tabular}{|c|c|c|c|c|c|c|}
\hline Rock & $\begin{array}{c}\text { Density } \\
\left(\mathrm{kg} \cdot \mathrm{m}^{-3}\right)\end{array}$ & $\begin{array}{l}\text { Bulk modulus } \\
\qquad(\mathrm{GPa})\end{array}$ & $\begin{array}{l}\text { Shear modulus } \\
(\mathrm{GPa})\end{array}$ & $\begin{array}{c}\text { Internal cohesion } \\
(\mathrm{MPa})\end{array}$ & $\begin{array}{c}\text { Internal friction } \\
\text { angle }\left({ }^{\circ}\right)\end{array}$ & $\begin{array}{c}\text { Tensile strength } \\
(\mathrm{MPa})\end{array}$ \\
\hline Fine sandstone & 2500 & 8.55 & 5.42 & 6.5 & 37 & 2.7 \\
\hline $\begin{array}{l}\text { Sandy mud } \\
\text { stone }\end{array}$ & 2300 & 5.68 & 3.73 & 4.2 & 35 & 1.2 \\
\hline Coal & 1317 & 2.85 & 2.13 & 2.5 & 33 & 0.56 \\
\hline $\begin{array}{l}\text { Sandy mud } \\
\text { stone }\end{array}$ & 2300 & 5.68 & 3.73 & 4.2 & 35 & 1.2 \\
\hline Fine sandstone & 2500 & 8.55 & 5.42 & 6.5 & 37 & 2.7 \\
\hline
\end{tabular}

4.2. Deformation and Failure Mechanism of Surrounding Rock in the Mining-Influenced Roadway. Figure 6 shows the morphology of the surrounding rock plastic zone under different mining stress conditions. When the impact of mining is not considered $(\eta=1.2)$, the shape of the surrounding rock plastic zone is similar to the butterfly shape, the size of the maximum plastic zone of surrounding rock above the roof is $1.6 \mathrm{~m}$, and the maximum plastic zone sizes of the floor and the side surrounding rock are both $1.4 \mathrm{~m}$. When $P_{1}$ remains unchanged and $P_{3}$ increases by 2 times $(\eta=0.6)$, the shape of the surrounding rock plastic zone around the roadway is similar to a horizontal ellipse, the maximum size of the plastic zone above the roof is reduced to $0.8 \mathrm{~m}$, the maximum size of the plastic zone at the sidewall increases to $2.4 \mathrm{~m}$, and the size of the plastic zone on the floor is reduced to $0.6 \mathrm{~m}$. When $P_{1}$ is unchanged and $P_{3}$ 
TABLe 2: Simulation plan with different mining coefficients.

\begin{tabular}{lcccc}
\hline Number & $D_{\zeta 1}$ & $D_{\zeta 3}$ & $\begin{array}{c}\text { Surrounding rock ratio } \\
\eta\left(D_{\zeta 1} P_{1} / D_{\zeta 3} P_{3}\right)\end{array}$ & $\alpha\left(^{\circ}\right)$ \\
\hline $\mathrm{a}$ & 1.0 & 1.0 & 1.2 & \\
$\mathrm{~b}$ & 1.0 & 2.0 & 0.6 & \\
$\mathrm{c}$ & 1.0 & 3.0 & 0.4 & 0 \\
$\mathrm{~d}$ & 1.0 & 4.0 & 0.3 & \\
$\mathrm{e}$ & 2.0 & 1.0 & 2.4 & \\
$\mathrm{f}$ & 3.0 & 1.0 & 3.6 & \\
$\mathrm{~g}$ & 4.0 & 1.0 & 4.8 & \\
\hline
\end{tabular}

TABLE 3: Simulation plan with different angles of principal stress.

\begin{tabular}{cccc}
\hline Number & $D_{\zeta 1}$ & $D_{\zeta 3}$ & $\alpha\left(^{\circ}\right)$ \\
\hline $\mathrm{a}$ & & & 0 \\
$\mathrm{~b}$ & & & 15 \\
$\mathrm{c}$ & \multirow{2}{*}{1.0} & 2.5 & 30 \\
$\mathrm{~d}$ & & & 45 \\
$\mathrm{e}$ & & & 60 \\
$\mathrm{f}$ & & 75 \\
$\mathrm{~g}$ & & & 90 \\
\hline
\end{tabular}

increases by 3 times $(\eta=0.4)$, the shape of the plastic zone of the surrounding rock of the roadway is a variant butterfly, and shoulders of the surrounding rock on the roof and floor are damaged with the maximum plastic failure depth of $1.6 \mathrm{~m}$, and the plastic zone of the surrounding rock at sides deforms on a large scale with the maximum failure depth of $3 \mathrm{~m}$. When $P_{1}$ is unchanged and $P_{3}$ increases by 4 times $(\eta=0.3)$, the plastic zone of the surrounding rock in the roadway has an irregular butterfly shape, the plastic failure at the shoulders on roof and floor surrounding rock is more serious with the maximum failure depth of $2 \mathrm{~m}$, and the failure area of the plastic zone in sidewall surrounding rock is extremely large with the horizontal failure depth of $4.6 \mathrm{~m}$ and the vertical failure length of $17 \mathrm{~m}$. When $P_{1}$ increases by 2 times and $P_{3}$ remains unchanged $(\eta=2.4)$, the shape of the overall surrounding rock plastic zone in the roadway is irregular, the plastic zone on the roof and floor is arched with a maximum size of $2.8 \mathrm{~m}$, and the plastic zone of the surrounding rock on the sidewall presents a "concave" shape with a maximum size of $2 \mathrm{~m}$. When $P_{1}$ increases by 3 times and $P_{3}$ is unchanged $(\eta=3.6)$, the shape of the overall plastic surrounding rock zone in the roadway is irregular; the failure area of the plastic zone in roof surrounding rock is extremely large with the vertical failure depth of $4.6 \mathrm{~m}$ and the horizontal failure length of $22.6 \mathrm{~m}$, the plastic zone in the sidewall surrounding rock presents a "concave" shape, with a maximum size of $2.8 \mathrm{~m}$, and the plastic zone of the floor surrounding rock has a large failure area with a vertical failure depth of $6 \mathrm{~m}$ and a horizontal failure length of $21.8 \mathrm{~m}$. When $P_{1}$ increases by 4 times and $P_{3}$ remains unchanged $(\eta=4.8)$, the shape of the overall plastic surrounding rock zone in the roadway remains irregular, and the length and depth of the damaged area are extremely large; the damaged area of surrounding rock on the roof is large with the vertical depth of $5.2 \mathrm{~m}$ and the horizontal damage length of $25 \mathrm{~m}$, the damage depth in the sidewall surrounding rock can reach $13.6 \mathrm{~m}$, and the damaged area of surrounding rock on the floor is also large with the vertical depth of $10 \mathrm{~m}$ and the horizontal length of $37.4 \mathrm{~m}$.

The change law of the plastic zone of surrounding rock after the change of principal stress is basically consistent with the theoretical calculation results. When the vertical principal stress is large, the plastic failure mainly occurs at the side, and when the horizontal principal stress is large, the plastic failure mainly occurs at the roof and floor. When the confining pressure ratio is high to a certain extent or low to a certain extent, the plastic zone of surrounding rock is severely damaged. This is the main reason of roof subsidence, side bulge, and floor heave in the mining roadway.

Figure 7 shows the different morphologies of the surrounding rock plastic zone when the magnitude of principal stress is unchanged and the direction of the stress deflects with the angle ranging from $0^{\circ}$ to $90^{\circ}$. When the principal stress does not deflect, the plastic zone is basically arch shaped with the roof plastic zone's size of $0.8 \mathrm{~m}$, the side plastic zone's size of $2.6 \mathrm{~m}$, the floor zone's size of $0.4 \mathrm{~m}$, and the plastic zone size of $2.6 \mathrm{~m}$ at the bottom corners, which can be seen from Figure 7(a); when the principal stress deflects by $15^{\circ}$, the morphology of the surrounding rock plastic zone changes; the depth of the roof plastic zone increases, and the shape of the roof plastic zone varies, and the roof plastic failure near the left sidewall is more serious with the maximum failure depth of $2 \mathrm{~m}$, the plastic zone on the sidewall hardly changes, and floor plastic failure near the right sidewall is more severe with the maximum failure depth of $2.2 \mathrm{~m}$, which is shown in Figure 7(b); when the principal stress deviates by $30^{\circ}$, the roof plastic zone continues to expand, the maximum damaged area approaches from the roof s left side to the roof s center, with a maximum size of $2.6 \mathrm{~m}$, the depth of plastic failure at sides increases, with the maximum size of $3.2 \mathrm{~m}$, a sharp corner appears in the plastic zone, the area of the floor plastic zone increases, and the maximum failure area approaches from the floor's right side to the center, with a maximum size of $2.8 \mathrm{~m}$, as shown in Figure $7(\mathrm{c})$; when the principal stress deviates by $45^{\circ}$, the plastic zone of the surrounding rock also deflects; the maximum failure zone on the roof reaches the middle of the roof with the maximum size of $2.8 \mathrm{~m}$, the roof plastic zone continues to expand with the maximum failure zone approaching from the left to the middle on the roof, with the maximum size of $2.6 \mathrm{~m}$, the sharp corner of the side plastic zone reaches the center of the side with the maximum size of $3 \mathrm{~m}$, and the maximum floor failure zone reaches the floor's middle, with the maximum size of $2.8 \mathrm{~m}$, as shown in Figure $7(\mathrm{~d})$; when the principal stress deviates by $60^{\circ}$, the maximum failure depth of the roof plastic zone is $3 \mathrm{~m}$, the area of the side plastic zone slightly reduced with the maximum size of $2.8 \mathrm{~m}$, the sharp corner approaches to the roof, and the maximum failure depth of the floor plastic zone is $2.8 \mathrm{~m}$, as shown in Figure 7(e); when the principal stress deviates by $75^{\circ}$, the maximum failure depth of the roof plastic zone is $2.8 \mathrm{~m}$, the area of the sidewall plastic zone continues to reduce with the maximum size of $2.4 \mathrm{~m}$, the sharp corner continues to approach to the roof, and the 


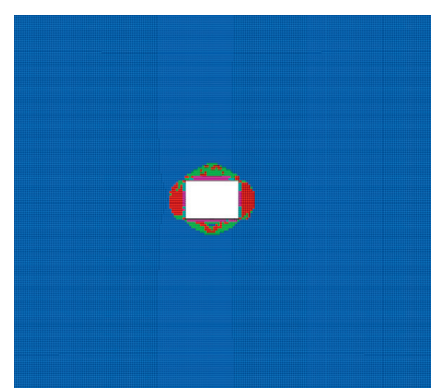

(a)

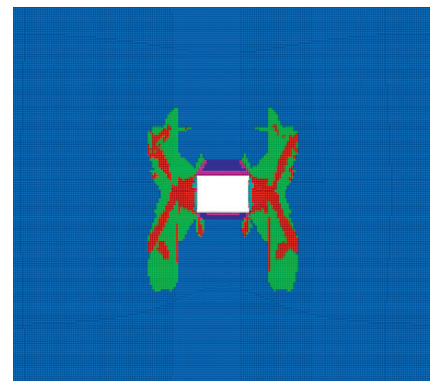

(d)

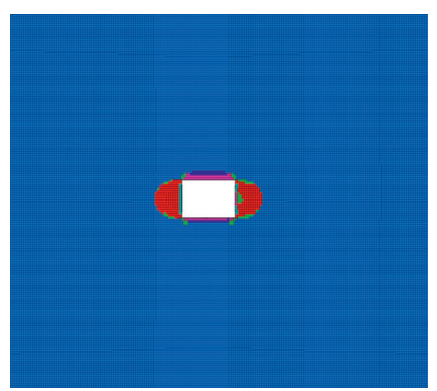

(b)

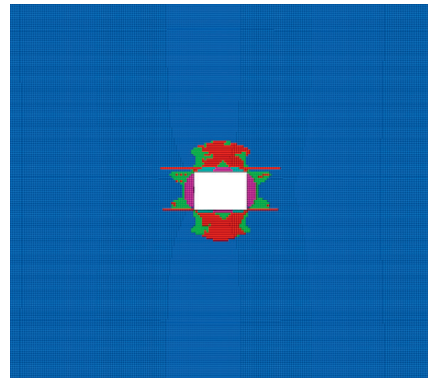

(e)

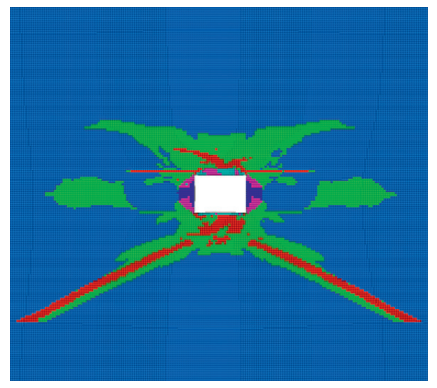

(g)

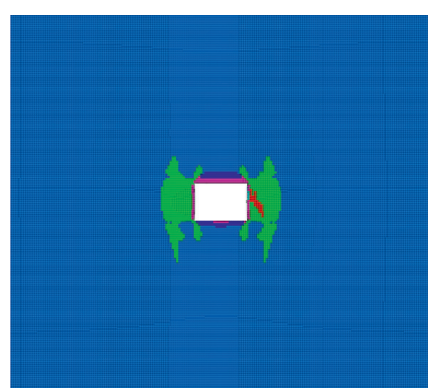

(c)

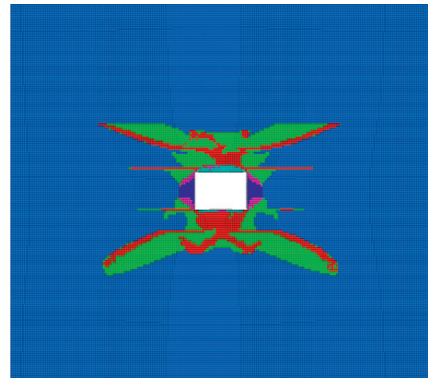

(f)

FIGURE 6: Morphology distributions of the surrounding rock plastic zone in the roadway influenced by stresses with different magnitudes.

maximum failure depth of the floor plastic zone is $2.8 \mathrm{~m}$, as shown in Figure 7(f); when the principal stress deviates by $90^{\circ}$, the maximum failure depth of the roof plastic zone is $2.8 \mathrm{~m}$, and the sidewall plastic zone decreases with the maximum of $2.0 \mathrm{~m}$, the side plastic zone transfers to the roof and floor, and the maximum failure depth of the floor plastic zone is $2.8 \mathrm{~m}$, as shown in Figure $7(\mathrm{~g})$.

In summary, the plastic zone morphology also changes when the principal stress angle changes from $0^{\circ}$ to $90^{\circ}$. The plastic zone of the side transfers to the top and bottom plate. The plastic zone of the side shows a decreasing trend, and the plastic zone of the roof shows an increasing trend. However, the maximum value of the plastic zone is stable within a certain range. It can be seen that when the principal stress continues to deflect, the overall shape of the plastic zone will transfer from the top and bottom to the two sides. The change of the principal stress direction causes the change of plastic zone morphology of surrounding rock.

\section{Discussion}

The deformation and failure of surrounding rock in the mining roadway are mainly caused by the change of the surrounding rock stress field. Therefore, the surrounding rock of the mining roadway can be controlled by adjusting the mining stress field to improve the plastic zone. The plastic zone size of surrounding rock can be reduced after stress adjustment. Finally, the stability of the broken rock mass in the plastic zone is maintained employing a roadway support. The support can prevent the broken rock from falling and instability in the plastic zone of surrounding rock. With existing technology, we can optimize the production layout. The methods of optimizing mining layout include mining sequence of the coal seam, reasonable selection of roadway position, and adjustment of coal pillar size. In this way, the stress environment of the roadway can be improved to achieve the stability of reducing the size of the plastic zone of the roadway.

Currently, several supporting means are applied to protect the mining-influenced roadway, such as anchor bolts (cable) support, grouting reinforcement, and frame support. And, the anchor bolt (cable) support method is most widely applied to increase support resistance and to reduce the roof subsidence amount. In practice, when the method of anchor bolt (cable) support is applied, more anchor cables are used. The increasing cost does not bring a significant control 


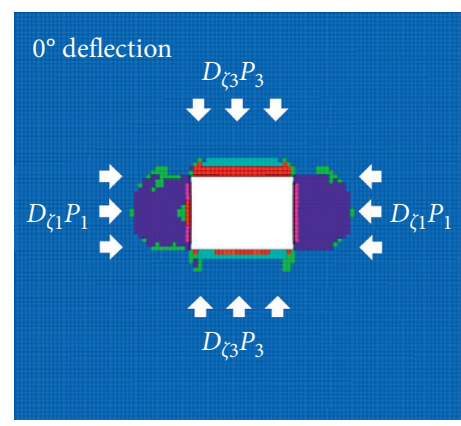

(a)

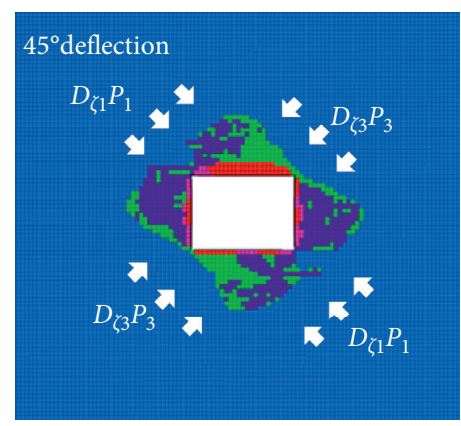

(d)

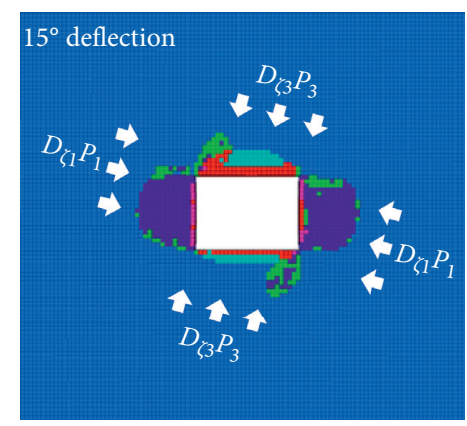

(b)

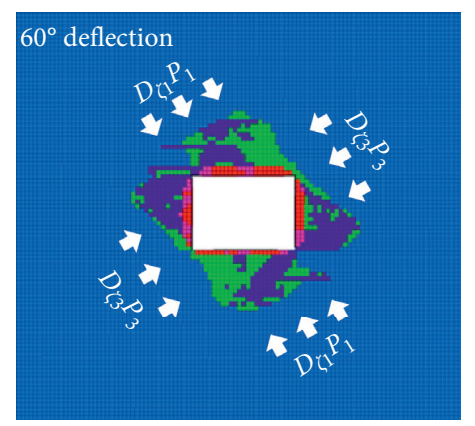

(e)

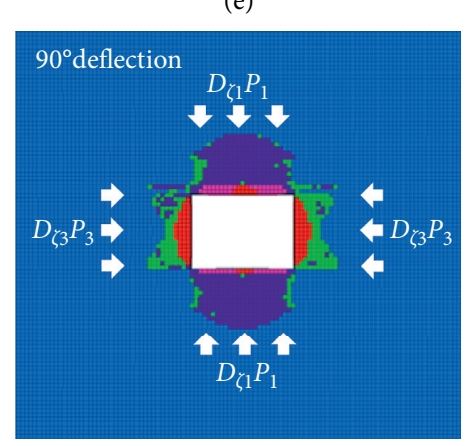

(g)

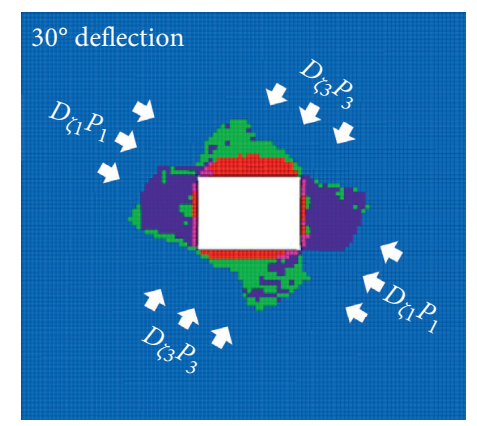

(c)

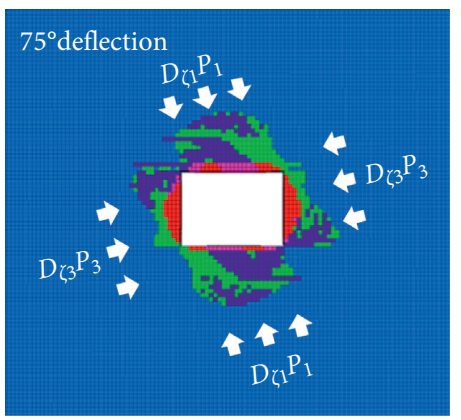

(f) 


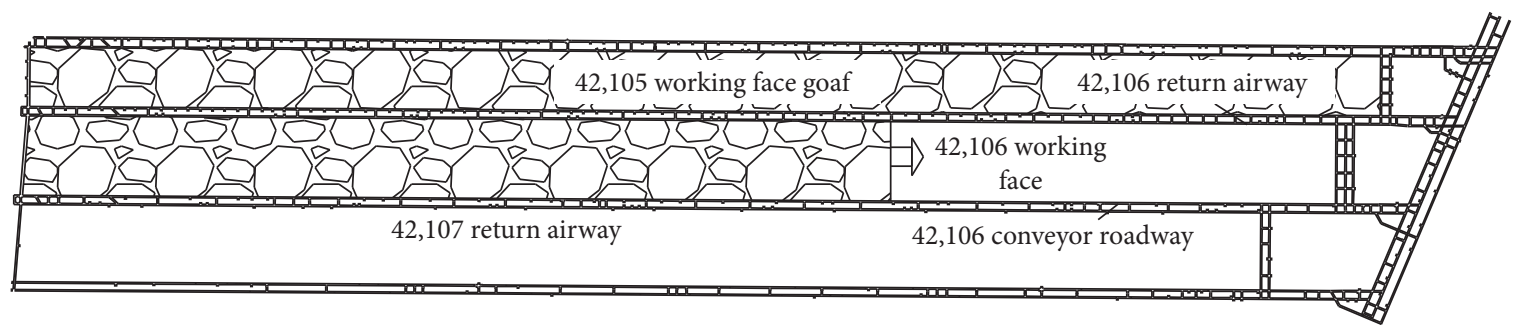

FIgURE 8: Layout of 42,106 working face.

coal seam is $389 \mathrm{~m}$. The thickness of the direct top is $10-11 \mathrm{~m}$, which is sandy mudstone, the thickness of the basic top is $22-23 \mathrm{~m}$, and the thickness of the direct bottom is $10-12 \mathrm{~m}$, which is sandy siltstone.

There is almost no deformation and failure in the 42,106 return air roadway in the process of excavation. However, after the mining of the 42,105 working face, the 42,106 return air roadway was located in the area behind the working face, and severe deformation and failure occurred under the influence of the mining of this working face, as shown in Figure 9. The roof of the advanced support section of the roadway has significant sag, with the maximum sag up to $300 \mathrm{~mm} \sim 500 \mathrm{~mm}$, as shown in Figure 9(a). The maximum deformation of the side under the influence of mining can reach $1800 \mathrm{~mm}$, resulting in the collapse of the anchor cable and the failure of support, as shown in Figure 9(b). The floor also suffered severe deformation, which seriously affected the normal production, as shown in Figure 9(c).

\subsection{Deformation and Failure Mechanism of the Return Air} Roadway. Based on the above analysis of the failure form and characteristics of the surrounding rock in the 42,106 return air roadway, it is believed that mechanical stress environment is the main factor affecting the deformation of the roadway. Two mining activities (mining in the 42,105 working face and mining in the 42,106 working face) make the stress environment worse and more complex. The irregular-shaped plastic zone is generated in the roadway affected by the high-deviatoric stress field. Due to the change of the principal stress direction, the maximum plastic zone is unevenly distributed, causing the nonuniform deformation of the roadway. As shown in above analysis, the deformation of surrounding rock in the 42,106 return air roadway is one of the most typical kind of mining-influenced roadway deformation. The mechanism of roadway's deformation and failure can be summarized as follows: affected by the mining deviatoric stress, the confining pressure ratio becomes larger or smaller, the malignant development happens in the surrounding rock plastic zone with the changed morphology of the plastic zone and increased size, deflection of the surrounding plastic zone is caused by the different directions of the principal stress, and the nonuniform distribution of roadway surrounding rock occurs; affected by the secondary mining activity, the plastic zone further expands to the deep rock mass, leading the serious deformation and failure of surrounding rock, such as roof falling, sidewall collapse, floor heave, and severe shrinkage of the cross section (Figure 10).

\subsection{Support Parameters of the Return Air Roadway}

(1) Roof support: the method of "left-hand twist threaded steel bars without the longitudinal rib for rock-anchor bolt + steel net + anchor cable $+\Pi$-type steel stripe" is applied. The size of left-hand twist threaded steel bars without the longitudinal rib for rock-anchor bolts is $\Phi 22 \times 2200 \mathrm{~mm}, 6$ sets of bolts are posited in each row in rectangular arrangement and row spacing between bolts is $1100 \times 1000 \mathrm{~mm}$; the size of steel nets is $\Phi 6.5 \times 5800 \times 1100 \mathrm{~mm}$, the size of nets is $150 \times 150 \mathrm{~mm}$ and the size of steel pallets is $150 \times 150 \times 10 \mathrm{~mm}$; the size of anchor cables is $\Phi 21.6 \times 8000 \mathrm{~mm}$, and the size of steel cable pallet is $200 \times 140 \times 10 \mathrm{~mm}$; the size of $\Pi$-type steel stripes with 5 meshes is $4500 \times 140 \times 10 \mathrm{~mm}$; 3 sets of equipment packages are posited in each row in rectangular arrangement and the row spacing between packages is $2000 \times 2000 \mathrm{~mm}$; the anchor cables are arranged on the $\Pi$-type steel stripes.

After the primary mining, the reinforcement support with anchor cables is carried out. Parameters of equipment used in the first reinforcement support are as follows: the size of anchor cables is $\Phi 21.6 \times 8000 \mathrm{~mm}$, the size of steel cable pallets is $200 \times 140 \times 10 \mathrm{~mm}$, and the size of $\Pi$-type steel stripes with five meshes is $4500 \times 140 \times 10 \mathrm{~mm}$; 3 sets of equipment packages are posited in each row in rectangular arrangement, the row spacing is $2000 \times 2000 \mathrm{~mm}$, and the anchor cables are arranged on the П-type steel stripes. Parameters of equipment used in the second reinforcement support are as follows: the size of anchor cables is $\Phi 21.6 \times 8000 \mathrm{~mm}$, the size of steel cable pallets is $200 \times 140 \times 10 \mathrm{~mm}$, the size of $\Pi$-type steel stripes with five meshes is $4500 \times 140 \times 10 \mathrm{~mm}$, and the steel stripes are posited in axial arrangement; two sets of equipment packages are posited in each row in rectangular arrangement, the row spacing is $2000 \times 2000 \mathrm{~mm}$, and the anchor cables are arranged on the П-type steel stripes, as shown in Figures 10(a) and 10(b).

(2) Positive side support: the support method of "glassreinforced plastic anchor bolt + wood plate + plastics-steel plastic net with double resistance." The size of glass-reinforced plastic anchor bolts is $\Phi 24 \times 2100 \mathrm{~mm}$, five sets of bolts are posited in a row in rectangular arrangement, and the row spacing of bolts is $800 \times 1000 \mathrm{~mm}$; the material of the round 


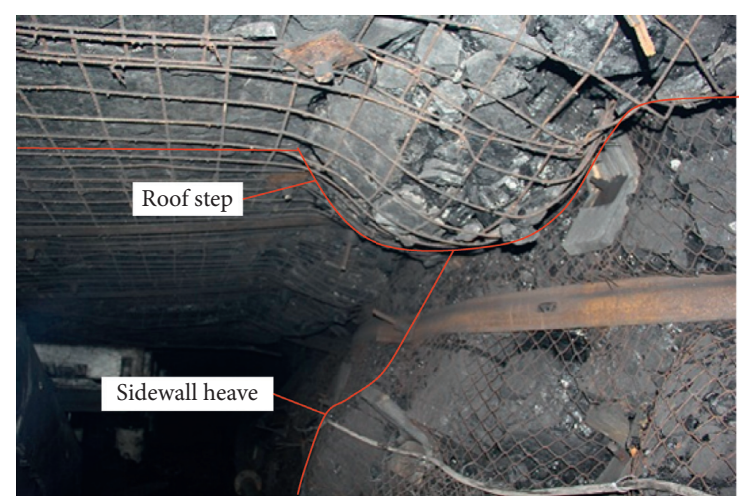

(a)

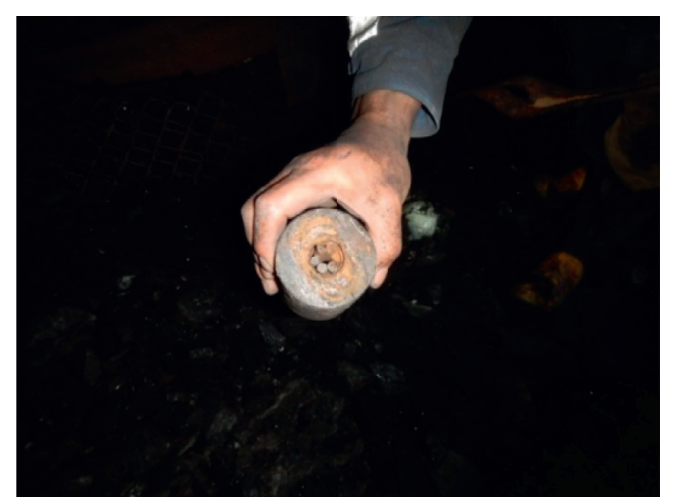

(b)

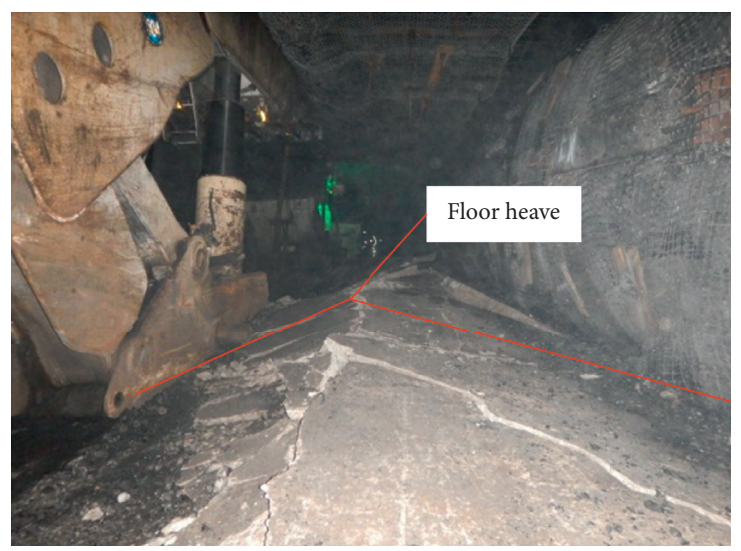

(c)

Figure 9: Deformation and failure of surrounding rock in the 42,106 return air roadway. (a) Floor and sides' deformation. (b) Broken anchor cable. (c) Floor deformation.

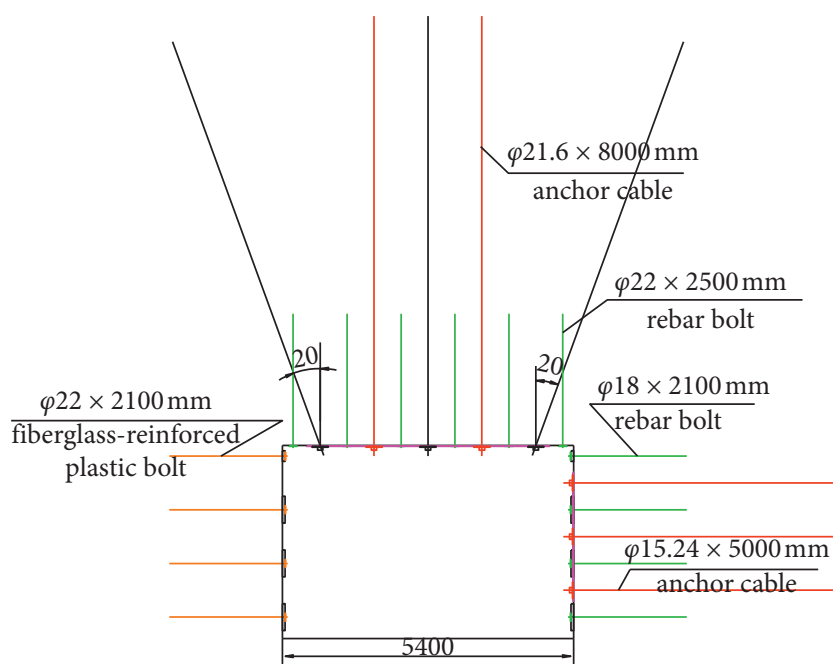

(a)

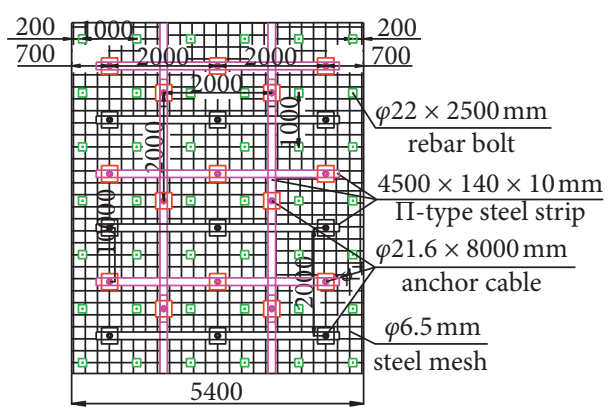

(b)

Figure 10: Continued. 


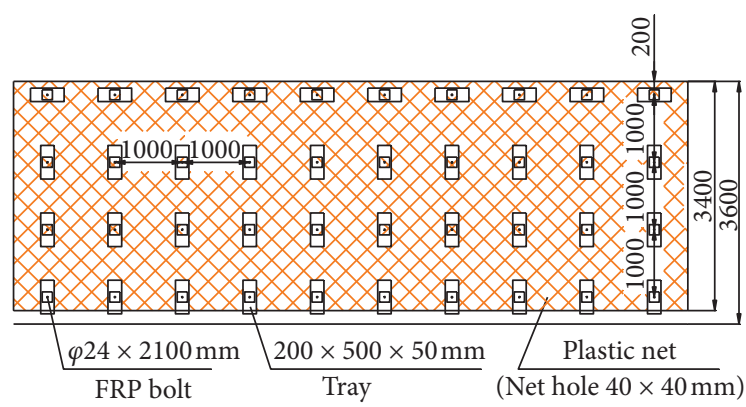

(c)

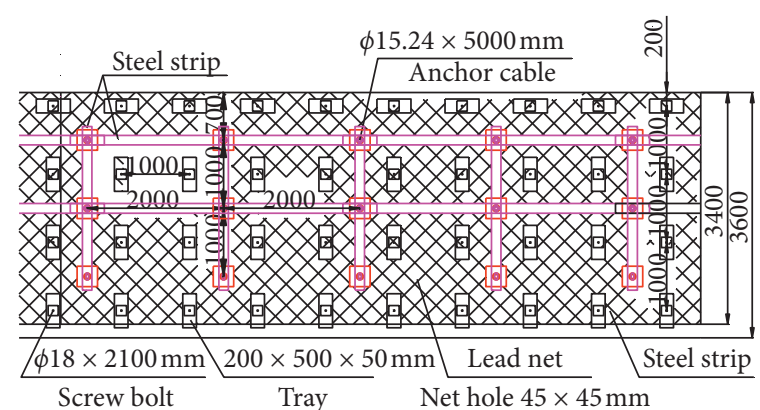

(d)

Figure 10: Support of the 42,106 return air roadway. (a) Roadway section diagram. (b) Plane diagram of the roof. (c) Positive sidewall section diagram. (d) Plane diagram of the negative sidewall.

anchor bolt plates is the glass fiber-reinforced plastic, the size of wood plates is $500 \times 200 \times 50 \mathrm{~mm}$, the size of plastics-steel plastic nets with double resistance is $1200 \times 4200 \mathrm{~mm}$, and the size of nets is $40 \times 40 \mathrm{~mm}$, which are shown in Figures 10(a) and 10(c).

(3) Negative side support: the method of "rebar bolt + wood plate + rhombic net" is adopted. The parameters of equipment used in this support are as follows: the size of rebar bolts is $\Phi 18 \times 2100 \mathrm{~mm}$, five sets of bolts are posited in a row in rectangular arrangement, and the row spacing of bolts is $800 \times 1000 \mathrm{~mm}$; the size of steel plates is $150 \times 150 \times 10 \mathrm{~mm}$, the size of wood plates is $500 \times 200 \times 50 \mathrm{~mm}$, the rhombic nets are $1200 \times 4200 \mathrm{~mm}$, and the size of meshes is $45 \times 45 \mathrm{~mm}$.

After the primary mining, the supplement support with anchor cables is carried out. The parameters of equipment used in this support are as follows: the size of anchor cables is $\Phi 15.24 \times 5000 \mathrm{~mm}$, the size of anchor cable steel plates is $200 \times 140 \times 10 \mathrm{~mm}$, and the sizes of two kinds of $\Pi$-type steel stripes are $4500 \times 140 \times 10 \mathrm{~mm}$ and $2400 \times 140 \times 10 \mathrm{~mm}$; three sets of equipment packages are posited in a row in rectangular arrangement, with the row spacing of $1000 \times 2000 \mathrm{~mm}$, and the anchor cables are arranged on the $\Pi$-type steel stripe, as shown in Figures 10(a) and 10(d).

The method of fractional stress yielding support can reduce the pressure to prevent a large number of fracture of anchor cables, which effectively stops the malignant expansion of the surrounding rock plastic zone, controls the broken rock falling, and eliminates the risk of roof collapse.

\section{Conclusion}

(1) The influence of mining on the distribution of plastic zone morphology of roadway surrounding rock is obtained by theoretical calculation. The shape and size of the plastic zone change with the change of stress. The critical value of the confining pressure ratio $\eta$ is 1 . The extreme increase or decrease of $\eta$ will lead to the sharp instability of surrounding rock.
When the principal stress direction changes, the plastic zone morphology will be deflected.

(2) The deformation and failure mechanism of surrounding rock of the mining roadway are revealed. When the vertical principal stress is greater, the plastic zone is mainly at the side, and when the horizontal principal stress is greater, the plastic zone is at the top and bottom plate. When the confining pressure ratio is high or low to a certain extent, the plastic failure of surrounding rock is extremely serious. When the principal stress direction changes, the maximum plastic failure area of surrounding rock also changes. This explains why the mining roadway appears to have asymmetrical deformation and failure.

(3) The fractional support method of "yielding first and then resisting" is put forward. The method applies cable supplement support after mining instead of the one-off high strength support during roadway excavation, to control the malignant expansion of the surrounding rock plastic zone and prevent roof falling accidents.

(4) Based on the analysis of the failure modes and characteristics of 42,106 return air roadway surrounding rock in the Buertai mine, it is determined that the failure of surrounding rock in the 42,106 return air roadway is a typical deformation mode of surrounding rock in the mining-influenced roadway. The fractional stress yielding support is adopted to hobble the continuous malignant expansion of the surrounding rock plastic zone, which effectively eliminates the risk of roof falling.

\section{Data Availability}

The data used to support the findings of this study are available from the corresponding author upon request.

\section{Conflicts of Interest}

The authors declare that they have no conflicts of interest. 


\section{Acknowledgments}

The authors wish to sincerely thank various organizations for their financial support. This work was partially supported by the National Natural Science Foundation of China (Grant no. 51804118) and supported by the Fundamental Research Funds for the Central Universities (Grant no. 3142017108).

\section{References}

[1] H. P. Kang, "Spatial scale analysis on coalmining and strata control technologies," Journal of Mining and Strata Control Engineering, vol. 2, no. 2, pp. 5-30, 2020.

[2] H. P. Kang, G. Xu, B. M. Wang et al., "Forty years development and prospects of underground coal mining and strata control technologies in China," Journal of Mining and Strata Control Engineering, vol. 1, no. 1, 2019.

[3] K. Wang and F. Du, "Coal-gas compound dynamic disasters in China: a review," Process Safety and Environmental Protection, vol. 133, pp. 1-17, 2020.

[4] M. Shabanimashcool and C. C. Li, "Vertical stress changes in multi-seam mining under supercritical longwall panels," International Journal of Rock Mechanics \& Mining Sciences, vol. 106, pp. 39-47, 2013.

[5] P. Konicek, K. Soucek, L. Stas, and R. Singh, "Long-hole destress blasting for rockburst control during deep underground coal mining," International Journal of Rock Mechanics and Mining Sciences, vol. 61, no. 7, pp. 141-153, 2013.

[6] G. Feng and P. Wang, "Simulation of recovery of upper remnant coal pillar while mining the ultra-close lower panel using longwall top coal caving," International Journal of Mining Science and Technology, vol. 30, no. 1, pp. 55-61, 2020.

[7] M. Rezaei, M. F. Hossaini, and A. Majdi, "Development of a time-dependent energy model to calculate the mininginduced stress over gates and pillars," Journal of Rock Mechanics and Geotechnical Engineering, vol. 7, no. 3, pp. 306-317, 2015.

[8] C. Li, T. H. Huo, Z. Wu, K. Lü, and B. Zhang, "Mechanism and stability control of nonuniform and violent deformation of dynamic pressure roadway roof," Journal of Central South University (Science and Technology), vol. 51, pp. 1317-1326, 2020.

[9] L. Jiang, A. Sainoki, H. S. Mitri, N. Ma, H. Liu, and Z. Hao, "Influence of fracture-induced weakening on coal mine gateroad stability," International Journal of Rock Mechanics and Mining Sciences, vol. 88, pp. 307-317, 2016.

[10] X. Guo, Z. Zhao, X. Gao, X. Wu, and N. Ma, "Analytical solutions for characteristic radii of circular roadway surrounding rock plastic zone and their application," International Journal of Mining Science and Technology, vol. 29, no. 2, pp. 263-272, 2019.

[11] Z. Q. Zhao, N. J. Ma, X. F. Guo, X. D. Zhao, and L. Fan, "Falling principle and support design of butterfly-failure roof in large deformation mining laneways," Journal of China Coal Society, vol. 41, no. 12, pp. 2932-2939, 2016.

[12] X. Guo, Z. Zhao, X. Gao, Z. Ma, and N. Ma, "The criteria of underground rock structure failure and its implication on rockburst in roadway: a numerical method," Shock and Vibration, vol. 2019, pp. 1-12, 2019.

[13] N. J. Ma, X. D. Zhao, Z. Q. Zhao, J. Li, and X. F. Guo, "Stability analysis and control technology of mine roadway roof in deep mining," Journal of China Coal Society, vol. 40, pp. 2287-2295, 2015.

[14] C. Li, X. F. Guo, X. Y. Lian, and N. J. Ma, "Failure analysis of a pre-excavation double equipment withdrawal channel and its control techniques," Energies, vol. 13, no. 23, pp. 1-17, 2020.

[15] Y. Yuan, Y. Zhu, W. Wang, and W. Yu, "Failure mechanism of Mesozoic soft rock roadway in Shajihai coal mine and its surrounding rock control," International Journal of Mining Science and Technology, vol. 24, no. 6, pp. 853-858, 2014.

[16] Q. C. Zhao and B. J. Fu, "Study on loose zone testing and support technology of roadway surrounding rock affected by dynamic pressure," Journal of Mining and Strata Control Engineering, vol. 2, pp. 49-56, 2020.

[17] F. L. He and G. C. Zhang, "Deformation and failure mechanism and control technology of large section coal roadway subjected to severe mining dynamic load," Journal of Mining \& Safety Engineering, vol. 13, pp. 423-430, 2016.

[18] T. Zhang and Y. L. Wang, "Study on deformation evolution law and support technology of surrounding rock in multiple mining roadway," Journal of Mining and Strata Control Engineering, vol. 66-73, pp. 66-73, 2020.

[19] S. Y. Chen, C. S. Song, Z. B. Guo, J. Wang, and Y. Wang, "Asymmetric deformation mechanical mechanism and control countermeasure for deep roadway affected by mining," Journal of China Coal Society, vol. 41, pp. 246254, 2016.

[20] G. L. Hui, S. J. Niu, H. W. Jing, and M. Wang, "Physical simulation on deformation rules of god-side roadway subjected to dynamic pressure," Journal of Mining \& Safety Engineering, vol. 27, pp. 77-86, 2010.

[21] W. J. Gale and R. L. Blackwood, "Stress distributions and rock failure around coal mine roadways," International Journal of Rock Mechanics and Mining Sciences \& Geomechanics Abstracts, vol. 24, no. 3, pp. 165-173, 1987.

[22] M. F. Cai, "Key theories and technologies for surrounding rock stability and ground control in deep mining," Journal of Mining and Strata Control Engineering, vol. 2, no. 3, pp. 5-13, 2020.

[23] M. G. Qian, P. W. Shi, and J. L. Xu, Mining Pressure and Strata Control, China University of Mining and Technology Press, Xuzhou, China, 2010

[24] Z. Q. Ma, Y. D. Jiang, Y. Liu, W. S. Du, and D. Z. Kong, "Investigation on support pattern of a coal mine roadway under dynamic pressure of mining-a case study," Interational Journal of Oil, Gas and Coal Technology, vol. 18, no. 3/4, pp. 402-422, 2018.

[25] Z. Q. Zhao, Mechanism of Surrounding Rock Deformation and Failure and Control Method Research in Large Deformation Mining Roadway, China University of Mining and Technology, Beijing, China, 2014.

[26] X. F. Guo, "General shapes and criterion for surrounding rock mass plastic zone of round roadway," Journal of China Coal Society, pp. 1871-1877, 2016.

[27] X. Y. Yu, Z. S. Wang, Y. Yang, and X. W. Mao, "Movement rule of overburden in fully mechanized caving mining with thick depth and high mining height based on 3DEC," Journal of Mining and Strata Control Engineering, vol. 3, no. 1, pp. 28-38, 2021.

[28] F. Q. Gao, "Use of numerical modeling for analyzing rock mechanic problems in underground coal mine practices," Journal of Mining and Strata Control Engineering, vol. 1, no. 2, pp. 21-28, 2019. 
[29] N. J. Ma, Z. Q. Zhao, and J. C. Feng, "Technology of long bolt or roadway supporting in difficult conditions," Coal Science and Technology, vol. 41, pp. 117-121, 2013.

[30] C. Li, Z. Wu, W. L. Zhang, Y. H. Sun, C. Zhu, and X. H. Zhang, "A case study on asymmetric deformation mechanism of the reserved roadway under mining influences and its control techniques," Geomechanics and Engineering, vol. 22, no. 5, pp. 449-460, 2020. 